\title{
Folic Acid Supplementation Ameliorates Inflammation and Apoptosis in Ethanol-Induced Gastric Ulceration in Rats
}

 \\ ${ }^{1}$ School of Basic Medical Sciences, Igbinedion University, Okada, Nigeria \\ ${ }^{2}$ College of Medicine, University of Ibadan, Ibadan, Nigeria \\ Email: ajeigbe.kazeem@iuokada.edu.ng
}

How to cite this paper: Ajeigbe, K.O., Jaja,, L.E. Onifade, A.A., Obabueki, P.O. and Owonikoko, W.M. (2017) Folic Acid Supplementation Ameliorates Inflammation and Apoptosis in Ethanol-Induced Gastric Ulceration in Rats. Journal of Biosciences and Medicines, 5, 101-117. https://doi.org/10.4236/jbm.2017.512011

Received: September 23, 2017

Accepted: December 15, 2017

Published: December 18, 2017

Copyright $\odot 2017$ by authors and Scientific Research Publishing Inc. This work is licensed under the Creative Commons Attribution International License (CC BY 4.0).

http://creativecommons.org/licenses/by/4.0/

\begin{abstract}
Although the gastroprotective potential of folic acid has been reported, little is known about the role of inflammation and apoptosis in the said activity. This study, therefore, assessed lipid peroxidation (LPO), Neutrophil-lymphocyte ratio (NLR), C-reactive protein (CRP) as markers of inflammation and, p53 and $\mathrm{BCl}-2$ as markers of apoptosis in ethanol-induced gastric ulcer pretreated with Folic acid (FA) for twenty-one (21) days. Adult male Wistar rats were arranged into experimental groups ( $\mathrm{n}=5$ ) viz: 1 ) Control; 2) Ulcer control; 3 ) $2 \mathrm{FA}(2 \mathrm{mg} / \mathrm{kg}$ folic acid + Ulcer); 4) 3FA ( $3 \mathrm{mg} / \mathrm{kg}$ folic acid + Ulcer); 5) OMEP (20 mg/kg omeprazole + Ulcer); 6) 2FA + OMEP + Ulcer; and 7) 3FA + OMEP + Ulcer. Ulcer score, LPO, NLR, serum CRP were all determined one hour post ulcer induction. Paraffin gastric sections were stained first with $\mathrm{H} \& \mathrm{E}$, then immunostained for $\mathrm{p} 53$ and $\mathrm{BCl}-2$. Ethanol caused gastric lesion with an index of $3.0 \pm 0.2$. Ulcer severity and LPO was significantly decreased in the 2FA, 3FA, OMEP, 2FA + OMEP and 3FA + OMEP groups. NLR reduced significantly in the 2FA, 3FA, OMEP and OMEP + 3FA group. Qualitatively, there was absence of $\mathrm{C}$-reactive protein in the $2 \mathrm{FA}$ group while quantitatively, presence of CRP appeared sustained in the 3FA and OMEP treated groups. Unlike p53, the expression and labeling index of BCl-2 were significantly enhanced more in the FA and OMEP combination than OMEP alone. Folic acid ameliorates the development of gastric ulcer in rats via its anti-inflammatory and anti-apoptotic activities.
\end{abstract}

\section{Keywords}

Folic Acid, Lipid Peroxidation (LPO), Neutrophil-Lymphocyte Ratio (NLR) 


\section{Introduction}

Peptic ulcer disease (PUD) is a sore, injury or break in the architectural lining of the stomach, first part of the small intestine, or occasionally the lower esophagus. Naturally, it is as a result of imbalance between the aggressive damaging effects of gastric acid, pepsin, lipid peroxidation, refluxed bile, abnormal motility etc. and the defense mechanisms, which protect the gastric and duodenal mucosa [1] [2]. The exogenous aggressive factors like Helicobacter pylori, indiscriminate use of non-steroidal anti-inflammatory drugs (NSAIDs), alcohol abuse and smoking have also long been identified as major contributor in the pathogenesis of peptic ulcer disease [3]. Meanwhile, the mucosal defense consists of a complex network of components that functions with one another which includes mucus, antioxidants, surface-active phospholipids and bicarbonates, the epithelium, the microcirculation and sensory afferent neurons beneath the epithelium, the mucosal immune system and regenerative ability of the mucosa [4]. Simply, the mucosal defense refers to factors that enable endurance to frequent exposure to substances with wide range of $\mathrm{pH}$, osmolarity, cytotoxic agents and bacterial products capable of causing local and systemic inflammatory reactions, which play an important role in apoptotic process [5].

In fact, ulcer disease is a cell loss disorder occasioned by the stimulation of apoptosis or inhibition of cell proliferation [6]. Hence, gastric mucosal integrity is maintained by interplay of aggressive and defensive factors controlling apoptosis and cell proliferation. Pro-ulcerative (exogenous) factors which enhance oxidative stress through over production of reactive oxygen species are major stimuli for apoptosis [7]. p53, CD95 (Fas), BCl-2 family and caspases are the factors involved in the regulation of the balance between apoptosis and proliferation. The up-regulation of p53 [8], Fas [9] and down-regulation of BCl-2 [10] is indicative of increased cellular apoptosis.

Peptic ulcer disease is the most predominant of gastrointestinal diseases with various epidemiologic data showing its steady incidence rate increase in different parts of the world [11] [12] [13] [14]. In spite of improved hygiene and gastric anti-secretory treatment regimens, peptic ulcer still remains a very serious world-wide health problem because of recurrence or intractability. This may be associated with the inability of acid suppression and Helicobacter pylori eradication to achieve complete ulcer healing [15], which in turn has made long term use of the treatment regimens inevitable. However, long term anti-ulcer therapy presents adverse side effects including vascular dementia, risk of osteoporosis, anaemia, ulcerative colitis and antibiotic resistant infections [16] [17]. Meanwhile, for adequate gastroprotection, enhanced quality of healing and less adverse effect, several studies have suggested complementing existing therapy with dietary supplementation. This dietary supplementation includes such natural antioxidants as oregano, licorice, vitamin B6 and B12, melatonin, and folic acid [18] [19].

Folate is a water soluble B vitamin, deficiency of which appears to play an 
important pathogenic role in the development of anemia, atherosclerosis, neural tube defects (NTDs), adverse pregnancy outcomes, neuropsychiatric disorders, and cancer [20]. Folic acid is the completely oxidized monoglutamyl form of this vitamin that is used commercially in supplements and in fortified foods [21]. Folate is generally regarded as safe and has long been assumed to be purely beneficial and an ideal functional food component for disease prevention [22]. Previously, from our laboratory, we had reported gastric anti-secretory and anti-oxidative properties of folic acid against indomethacin-induced gastropathy [23] [24]. However, there is a still paucity of information on the role of inflammation and apoptosis in this beneficial activity of folic acid. We, therefore, present the roles of lipid peroxidation, Neutrophil-lymphocyte ratio, C-reactive protein, $\mathrm{p} 53$ and $\mathrm{BCl}-2$ in ethanol-induced gastric ulcer pretreated with folic acid and omeprazole.

\section{Materials and Methods}

\subsection{Animals}

Thirty-five (35) healthy male albino rats of Wistar strain weighing between 180 - 200 $\mathrm{g}$ were used in the study. They were housed under standard conditions of temperature $\left(23^{\circ} \mathrm{C} \pm 2^{\circ} \mathrm{C}\right)$; humidity $(55 \% \pm 15 \%)$ and $12 \mathrm{~h}$ light $(7.00 \mathrm{am}-7.00$ $\mathrm{pm})$. They were kept in plastic cages and fed with standard commercial rat pellets (Premier Feeds Limited, Nigeria). Each animal was deprived of food 24 - 36 hours before the start of the experiment but allowed water ad libitum.

\subsection{Drugs and Chemicals}

Folic acid tablets and omeprazole were obtained from Emzor Pharmaceutical Industries Ltd. and Standard Generics Ltd., Nigeria respectively. Serum C-reactive protein estimation kit was procured from Agappe Diagnostics, Switzerland. p53 and BCl-2 antibodies were obtained from Leica Biosystems, Nussloch, Germany. All other reagents were of analytical grade and obtained from British Drug House, Poole, UK.

\subsection{Experimental Design}

\subsubsection{Animal Grouping}

The animals were randomly divided into seven (7) groups of five rats each. The grouping was as follows:

1) Group One-Overall control. Normal saline (only) treated;

2) Group Two-Ulcer control; 90\% Ethanol only;

3) Group Three $-2 \mathrm{mg} / \mathrm{kg}$ Folic acid pre-treatment + Ulcer;

4) Group Four-3 mg/kg Folic acid pre-treatment + Ulcer;

5) Group Five-Omeprazole ( $20 \mathrm{mg} / \mathrm{kg})+$ Ulcer;

6) Group Six $-2 \mathrm{mg} / \mathrm{kg}$ Folic acid + Omeprazole $(20 \mathrm{mg} / \mathrm{kg})+$ Ulcer;

7) Group seven $-3 \mathrm{mg} / \mathrm{kg}$ Folic acid + Omeprazole (20 mg/kg) + Ulcer.

Animals were treated orally with folic acid (Groups Three and Four) for 
twenty-one days while omeprazole (Group Five) was given seven days prior to ulcer induction with $95 \%$ ethanol. Meanwhile, overall control rats (Group One) received distilled water, while ulcer control group (Group Two) received ethanol only. Groups Six and Seven had animals treated with folic acid $(2 \mathrm{mg} / \mathrm{kg}$ and 3 $\mathrm{mg} / \mathrm{kg}$ ) for twenty-one days and omeprazole for the penultimate seven days respectively. The lesions formed one hour after ethanol administration. Gastric tissues selected for biochemical analysis were used freshly, while those for histopathology were stored in $10 \%$ formalin. All studies on animal experimentation were conducted in accordance with the current Animal Care Regulations and standards approved by the Institute for Laboratory Animal Research (ILAR, 1996) and the experimental protocol approved by the Central Animal Facility And Ethics Committee of College of Health Sciences, Igbinedion University, Okada, Edo State, Nigeria.

\subsubsection{Ulcer Induction and Determination}

One hour after the oral administration of ethanol, the stomachs of all the experimental groups were opened along the greater curvature, washed in normal saline to remove debris and pinned for ulcer scoring. The severity score was assigned according to Haule et al. [25]: Score 0, no pathological change; Score 0.5, Hyperemia (red coloration); Score 1, Haemorrhagic spot; Score 2, 1 - 5 small ulcers (1 - $2 \mathrm{~mm}$ ); Score 3, more than five small ulcers or one medium ulcer (3 - 4 $\mathrm{mm}$ ); Score 4, two medium ulcers or one large ulcer (more than $4 \mathrm{~mm}$ ); Score 5, perforated ulcer. Afterwards, gastric tissues were excised for biochemical (lipid peroxidation), histological and immunohistochemical analysis.

\subsubsection{Biochemical Analysis}

Determination of malondialdehyde (MDA). The modification assay by Gutteridge and Wilkins [26] of Hunter et al., [27] method was employed. The principle of this method is based on malondialdehyde formation from the breakdown of polyunsaturated fatty acids which serves as a convenient index for the determination of the extent of the peroxidation reaction. Malondialdehyde when heated with thiobarbituric acid in the presence of trichloroacetic acid and hydrochloric acid gives a red species absorbing at $535 \mathrm{~nm}$. The stomach homogenate $(1 \mathrm{~mL})$ was heated for 15 minutes with $2 \mathrm{~mL}$ of TCA-TBA- $\mathrm{HCl}$ composed of $15 \mathrm{~g}$ of trichloroacetic acid (TCA), $0.375 \mathrm{~g}$ of thiobarbituric acid (TBA) and $0.25 \mathrm{~N}$ of hydrochloric acid. After cooling and centrifuge, absorbance of the supernatant of the sample was read at $535 \mathrm{~nm}$. The malondialdehyde concentration of the sample was calculated using extinction co-efficient of $1.56 \times 10^{5}$ $\mathrm{m}^{-1} \mathrm{~cm}^{-1}$ as follows:

$$
\text { TBARS Activity }=\frac{O . D \times V \times 1000}{a \times v \times I \times y}
$$

$O . D=$ Absorbance of the sample test at $535 \mathrm{~nm} ; V=$ Total volume of the reaction sample $(3 \mathrm{~mL}) ; a=$ molar estimation co-efficient of product, $1.56 \times 10^{5}$ $\mathrm{m}^{-1} \mathrm{~cm}^{-1} ; I=$ Light path, $1 \mathrm{~cm} ; y=\mathrm{mg}$ of tissue in the volume of sample used. 
The result was expressed as nanomoles MDA/mg wet tissue.

\subsubsection{Histopathological Studies}

Histological studies were performed according to the methods previously described by [28]. At autopsy, small pieces of tissues including ulcers were embedded in paraffin and sectioned at $5 \mu \mathrm{m}$ in an automated microtome. Haematoxylin and eosin (H \& E) staining was done for cytoarchitectural alteration, neutrophil infiltration. Tissue contraction, regeneration of the ulcerated mucosa, forming of granulated tissue, glands arrangement and inflammatory exudates were assessed under microscope [29]. The inflammatory cells infiltration assessment done subjectively using the scale below as suggested by Trevethick et al. [30]: $0=$ No infiltration; $1=$ Very mild infiltration; $2=$ Mild infiltration; $3=$ Moderate infiltration; $4=$ Marked infiltration.

\subsubsection{Immunohistochemical Studies}

Immunostaining was done by Avidin-biotin horseradish peroxidase method [31]. Briefly, the microwave antigen retrieval procedure was done in hot citric acid ( $\mathrm{pH} \mathrm{6)}$ ) for 15 minutes. After peroxidase activity block with $3 \%$ hydrogen peroxide $\left(\mathrm{H}_{2} \mathrm{O}_{2}\right)$ for $15 \mathrm{~min}$ and wash in PBS, protein blocking was performed using avidin for $15 \mathrm{~min}$, and endogenous biotin in tissue were blocked using biotin for another $15 \mathrm{~min}$. Incubation followed, thereafter, with the respective diluted primary antibody viz: p53 and BCl-2 antibodies (Leica Biosystems, Nussloch), diluted 1:100 for $60 \mathrm{~min}$. Excess antibody were washed off with PBS and a secondary antibody (LINK) were applied on sections for $15 \mathrm{~min}$. Sections were washed and the (LABEL) which is the horseradish peroxidase (HRP) were applied on the sections for $15 \mathrm{~min}$. Staining was later done by immersing in chromogen and counterstained in haematoxylin. Cells with specific brown colors are considered to be positive. Positive immunoreactive cells were quantified. \% Area and/or point counting of positive immunoreactive cells were estimated using Image J analysis software (NIH, USA). Point was performed on a captured image with the appropriate plug-in. A grid of intersecting lines, crosses or circular points was overlaid on an open image with the colour and size of choice. To apply a grid, we selected Plugin/Grid and a Reference window appeared. In the new window, we selected the desired Grid Type, Area per Point and Line Width. The grid displayed on the image allowed point counting. This was performed by two investigators independently, and less than $5 \%$ variance between the results of two counts observed. The labeling index (LI) was defined as a percentage of the positive nuclei over the total nuclei counted.

\subsubsection{Hematological Parameters Determination}

Before sacrifice, the animal's thorax was opened and approximately $2 \mathrm{ml}$ of blood were withdrawn by cardiac puncture (using a 21 gauge butterfly needle) and added to vials containing EDTA as an anti-coagulant. Hematological indices were determined using the Automated Mythic ${ }^{\mathrm{TM}} 18$ Hematology Analyzer at Igbinedion University Teaching Hospital (IUTH). The auto-analyzer was operated 
as instructed in the User's operational manual.

C-Reactive Protein Assay

Qualitative and semi-quantitative determination of C-reactive protein (CRP) in the rat serum was done using the protocol provided by the kits manufacturer. The assay was based on the principle of agglutination. The test specimen (serum) is mixed with CRP latex reagent and allowed to react. The serum was gotten as supernatant when whole blood collected stood undisturbed and later clotted at room temperature. If CRP concentration is greater than $0.6 \mathrm{mg} / \mathrm{dl}$ a visible agglutination is observed. If CRP concentration is less than $0.6 \mathrm{mg} / \mathrm{l}$, then no agglutination is observed.

Qualitative method: Briefly, one drop of serum was placed on the slide using disposable pipette provided with the kit. One drop of CRP latex reagent was added to the drop of the test specimen on the slide without letting the dropper tip touch the serum on the slide. The serum and CRP latex reagent was mixed uniformly over the entire circle using a mixing stick. The stopwatch was started immediately and the slide was rocked gently back and forth. Macroscopic examination was done at two minutes. Agglutination is a positive test result and indicates presence of detectable levels of CRP.

Semi-quantitative method: Serial dilutions $(1: 2,1: 4,1: 8,1: 16,1: 32,1: 64$ and so on) of the test sera found positive in the qualitative method was prepared using isotonic saline. One drop $(40 \mu \mathrm{L})$ of each dilution was pipette onto separate reaction circles on the slide. One drop of CRP latex reagent was added to each drop of the test specimen on the slide. The serum and CRP latex reagent was mixed uniformly over the entire circle using a mixing stick. The stopwatch was started immediately and the slide was rocked gently back and forth. Macroscopic examination was done at two minutes. Agglutination in the highest serum dilution corresponds to the approximate amount of CRP in $\mathrm{mg} / \mathrm{dl}$ present in the test specimen.

$$
C R P(\mathrm{mg} / \mathrm{dl})=S \times D
$$

where $S=$ Sensitivity of the reagent i.e. $0.6 \mathrm{mg} / \mathrm{dl}, D=$ Highest dilution of serum showing agglutination.

\subsection{Statistical Analysis}

Values are presented as Mean \pm SEM and subjected to one way analysis of variance (ANOVA) and Tukey test using GraphPad prism version 6.0 for windows from GraphPad software, San Diego, California, USA. P values $<0.05$ were regarded significant.

\section{Results}

\subsection{Development of Gastric Lesions}

Ethanol caused gastric lesions with a score of 3.0. Folic acid exhibited $27 \%$ and $30 \%$ reduction in ulcer severity at $2 \mathrm{mg} / \mathrm{kg}$ and $3 \mathrm{mg} / \mathrm{kg}$ pre-treatment. Moreover, folic acid and omeprazole combination had a more significant reduction in 


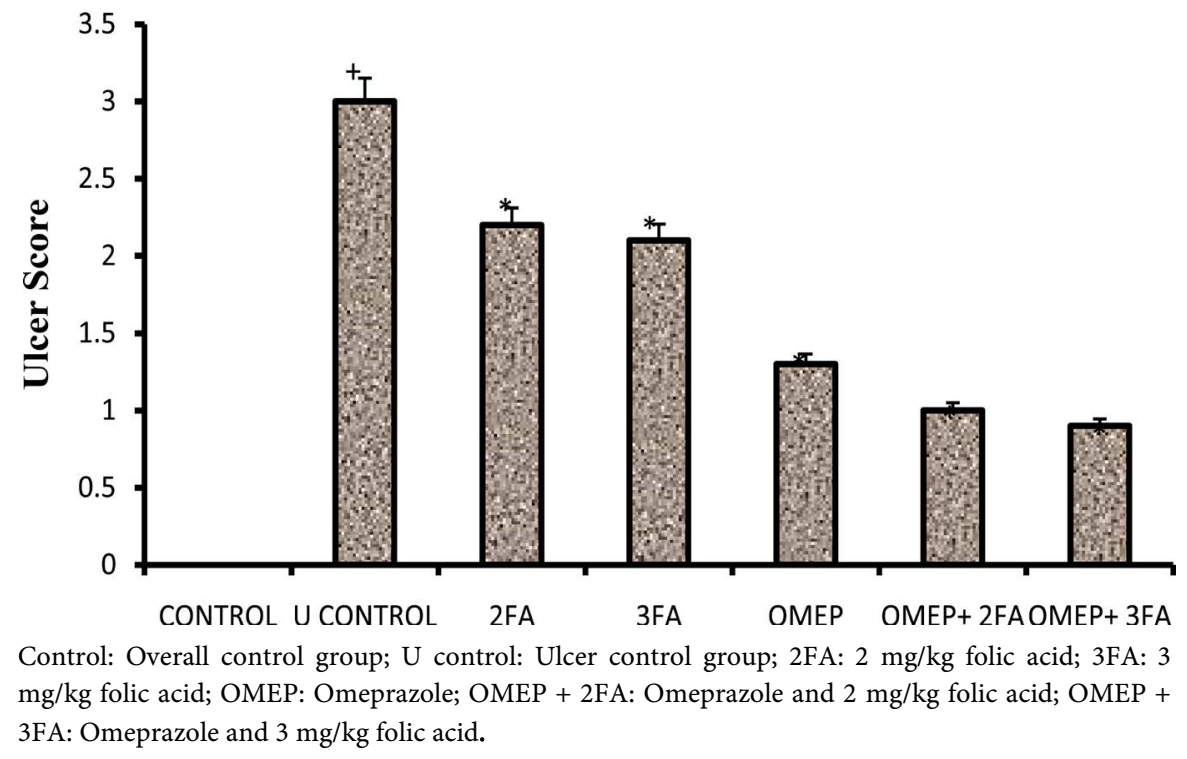

Figure 1. Gastric lesion score in ethanol-induced gastric mucosal injury pretreated with folic acid and omeprazole ( ${ }^{*} \mathrm{p}<0.05 \mathrm{cf}$ ulcer control).

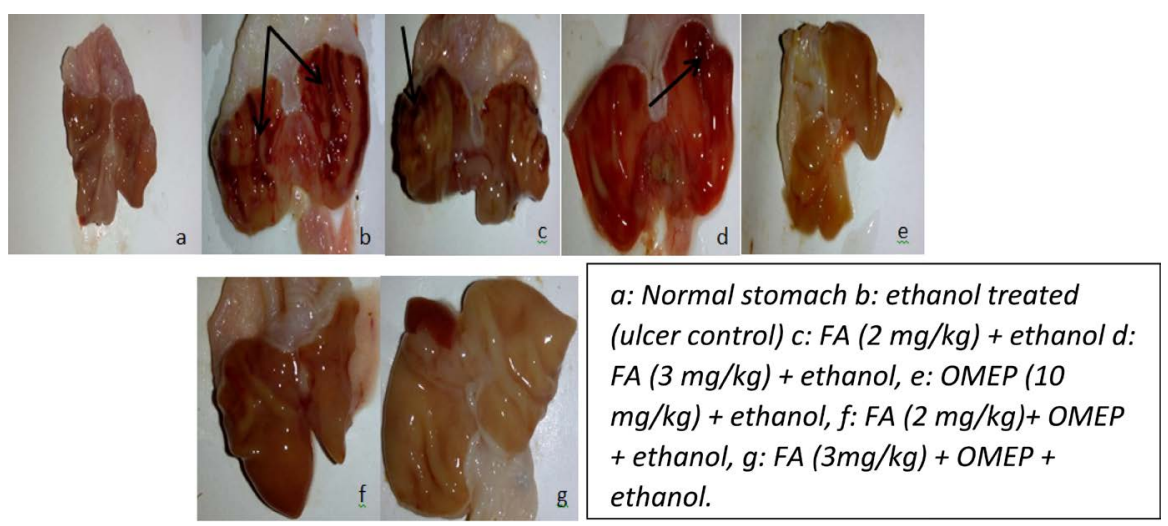

Plate 1. Macroscopic inspection of the effects of folic acid and omeprazole on ethanol induced gastric ulceration in rats. Arrow: Site of ulceration.

the severity at $67 \%$ and $70 \%$ respectively (Figure 1 ). The macroscopic view of the gastric mucosa in both the control and experimental groups is presented in Plate 1.

\subsection{Effect of Folic Acid and Omeprazole on Cyto-Architectural Alteration and Inflammatory Cells Infiltration Induced by Ethanol in Rats}

The normal stomach (control) showed no sign of inflammation or ulcer with a normal epithelial layer and an intact submucosa while the ulcer control group showed erosions and severe edema of the submucosa as well as mild congestion of the mucosa. There was an improvement in the distortions of the cyto-architecture upon treatment with folic acid and omeprazole (Plate 2). Moreover, the infiltration of inflammatory cells was significantly attenuated in the folic acid and omeprazole treated when compared with the ulcer control (Figure 2). 


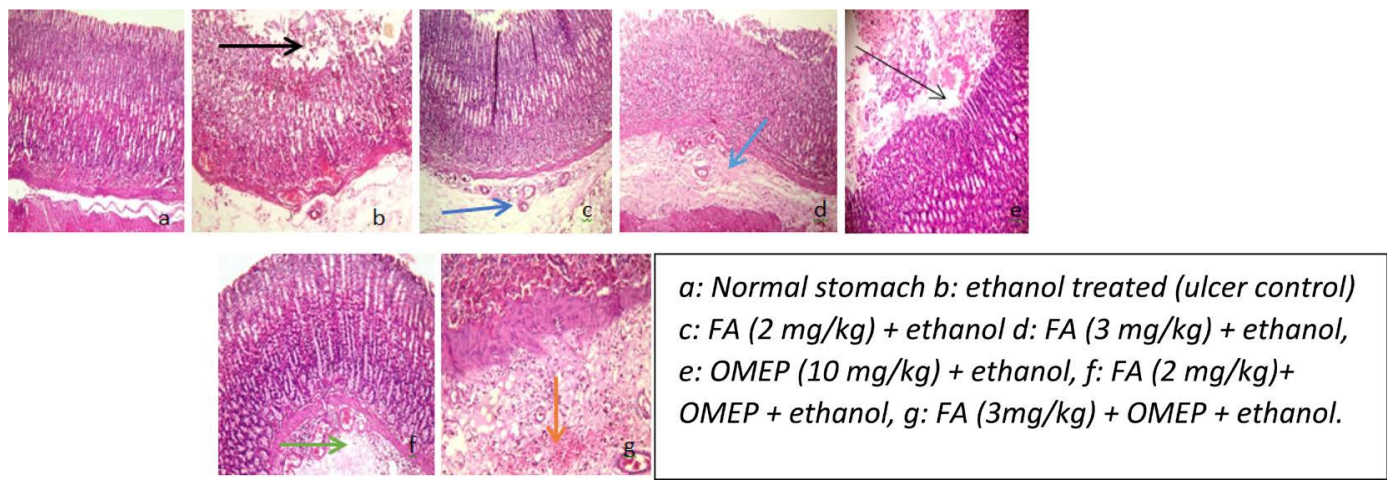

Plate 2. Effect of folic acid and omeprazole on cyto-architectural alteration induced by ethanol in the rat stomach (H \& E, $\times 100)$. Black arrow: Erosion; Dark blue: Congestion of submucosa; Light blue: Slight congestion; Slender black arrow: Slight erosion; Green: Congestion; Orange: Slight haemorrhage.

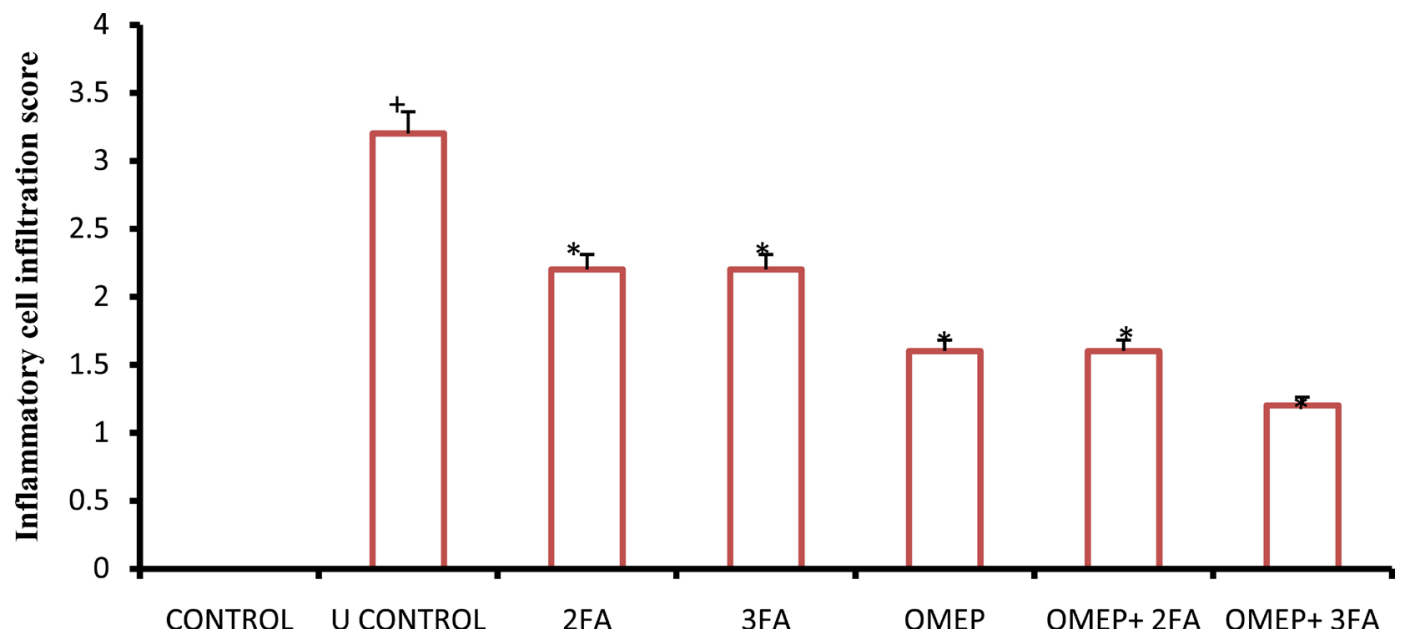

Figure 2. Effect of folic acid and omeprazole on infiltration score post ethanol administration in rats $\left({ }^{*} \mathrm{p}<\right.$ $0.05 \mathrm{cf}$ ulcer control).

\subsection{Effect of Folic Acid and Omeprazole on Lipid Peroxidation in Ethanol Induced Ulceration}

Lipid peroxidation is measured as the amount of malondialdehyde (MDA) in the gastric mucosa. Ethanol produced lipid peroxidation with marked increase in MDA concentration when compared with the normal stomach (Figure 3). The lipid peroxidation, however, was attenuated by $40.3 \%, 44.8 \%$ reduction in malondialdehyde (MDA) concentration, following pretreatment with $2 \mathrm{mg} / \mathrm{kg}$ and $3 \mathrm{mg} / \mathrm{kg}$ of folic acid respectively, while omeprazole did it to the extent of $52.4 \%$. Interestingly, the combination of folic acid and omeprazole afforded further significant reduction.

\subsection{Effect of Folic Acid and Omeprazole on White Blood Cell, Neutrophil-Lymphocyte Ratio (NLR)}

Ethanol caused an elevation in the white blood cell and neutrophil count, but decrease in lymphocytes. But, however, pre-treatment with folic acid and omeprazole attenuated this increase significantly (Table 1). Moreover, $2 \mathrm{mg} / \mathrm{kg}$ and 


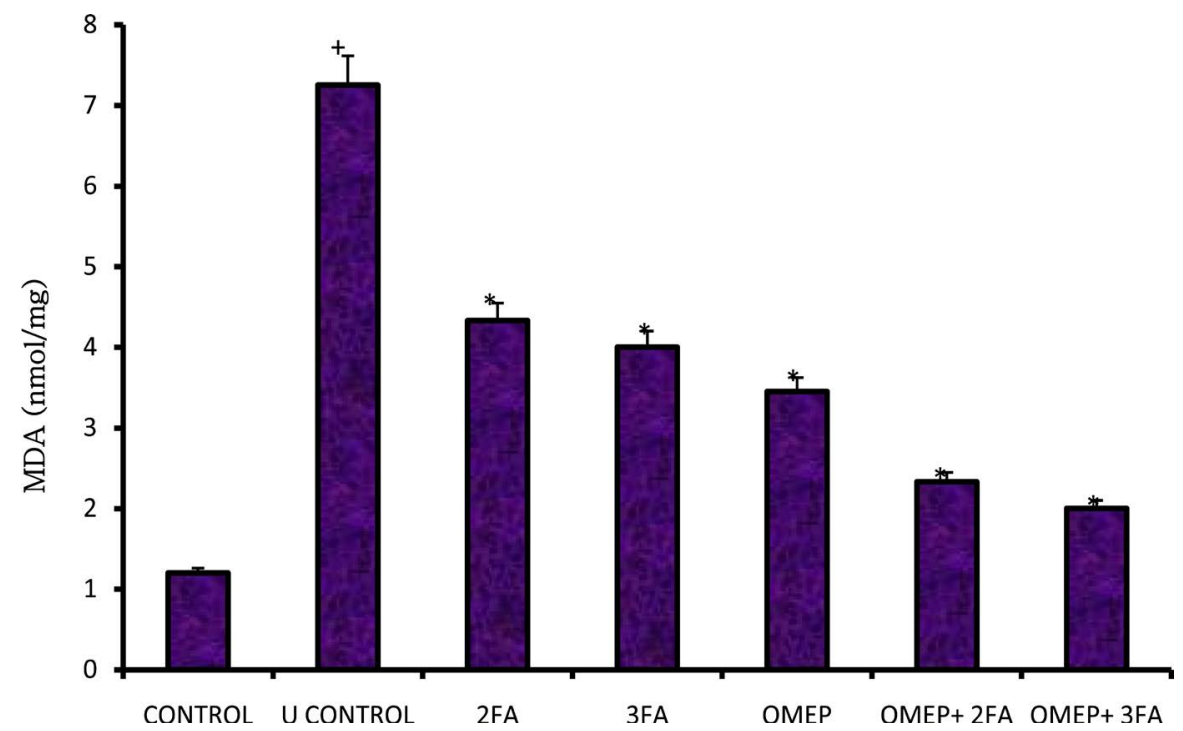

Control: Overall control group; U control: Ulcer control group; $2 \mathrm{FA}: 2 \mathrm{mg} / \mathrm{kg}$ folic acid; 3FA: 3 $\mathrm{mg} / \mathrm{kg}$ folic acid; OMEP: Omeprazole; OMEP + 2FA: Omeprazole and $2 \mathrm{mg} / \mathrm{kg}$ folic acid; OMEP + 3FA: Omeprazole and $3 \mathrm{mg} / \mathrm{kg}$ folic acid.

Figure 3. Effect of folic acid and omeprazole on lipid peroxidation in ethanol induced gastric ulceration in rats. $\left({ }^{+, *} \mathrm{p}<0.05 \mathrm{cf}\right.$ control and ulcer control respectively).

Table 1. Effect of folic acid and omeprazole on white blood cell count, neutrophil count and lymphocyte count after ethanol induced gastric injury.

\begin{tabular}{ccccc}
\hline S/N & Groups & $\begin{array}{c}\text { White blood cells } \\
\left(\times 10^{9} \text { Cells/L) }\right.\end{array}$ & $\begin{array}{c}\text { Neutrophils } \\
\left(\times 10^{9} \text { cells } / \mathrm{L}\right)\end{array}$ & $\begin{array}{c}\text { Lymphocytes } \\
\left(\times 10^{9} \text { Cells/L) }\right.\end{array}$ \\
\hline 1 & Control & $6.0 \pm 1.2$ & $3.2 \pm 0.5$ & $1.3 \pm 0.3$ \\
2 & U Control & $8.6 \pm 1.3^{+}$ & $6.1 \pm 0.9^{+}$ & $0.9 \pm 0.5^{+}$ \\
3 & 2FA & $6.6 \pm 1.2^{+}$ & $3.5 \pm 0.7^{*}$ & $1.2 \pm 0.3^{\star}$ \\
4 & 3FA & $5.3 \pm 0.3^{*}$ & $3.5 \pm 0.4^{*}$ & $0.7 \pm 0.1$ \\
5 & OMEP & $4.7 \pm 0.5^{*}$ & $3.3 \pm 0.4^{*}$ & $0.5 \pm 0.1$ \\
6 & OMEP+2FA & $6.9 \pm 0.8$ & $5.2 \pm 0.7$ & $0.6 \pm 0.1$ \\
7 & OMEP+3FA & $5.9 \pm 0.3$ & $3.9 \pm 0.4^{*}$ & $0.7 \pm 0.1$ \\
\hline
\end{tabular}

Values are expressed as Mean $\pm \mathrm{SEM}{ }^{+, *} p<0.05$ compare control and ulcer control respectively.

$3 \mathrm{mg} / \mathrm{kg}$ treatment reduced the increase in NLR by ethanol administration by $56.9 \%$ and $26.3 \%$ respectively (Figure 4 ).

\subsection{Effect of Folic Acid and Omeprazole on C-Reactive Protein (CRP) Concentration}

Qualitatively, the presence of C-reactive protein was observed in the ulcer control group, FA (3 mg/kg), omeprazole, and omeprazole + FA (3 mg/kg) group, and no trace in the $2 \mathrm{mg} / \mathrm{kg}$ folic acid treated (Table 2). It was later observed, after semi-quantification as shown in Figure 5, that the combination of $3 \mathrm{mg} / \mathrm{kg}$ folic acid and omeprazole treated groups showed higher values than the ulcer control group $(\mathrm{p}<0.05)$. 


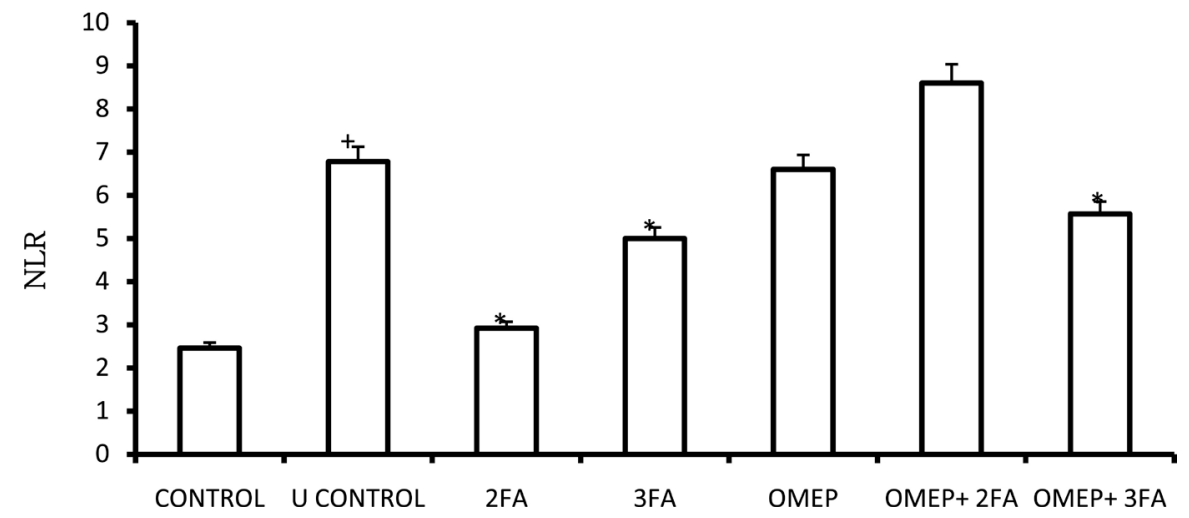

Control: Overall control group; $U$ control: Ulcer control group; $2 \mathrm{FA}: 2 \mathrm{mg} / \mathrm{kg}$ folic acid; 3FA: 3 $\mathrm{mg} / \mathrm{kg}$ folic acid; OMEP: Omeprazole; OMEP + 2FA: Omeprazole and $2 \mathrm{mg} / \mathrm{kg}$ folic acid; OMEP + 3FA: Omeprazole and $3 \mathrm{mg} / \mathrm{kg}$ folic acid.

Figure 4. Effect of folic acid and omeprazole on neutrophil-lymphocyte ratio post ethanol administration in rats $\left(^{+, *} \mathrm{p}<0.05 \mathrm{cf}\right.$ control and ulcer control respectively).

Table 2. Presence of C-reactive protein in folic acid and omeprazole treated rat serum post ethanol administration.

\begin{tabular}{ccccccc}
\hline Control & U Control & $2 \mathrm{FA}$ & $3 \mathrm{FA}$ & OMEP & OMEP + 2FA & OMEP + 3FA \\
\hline- & + & + & + & + & + & + \\
- & + & - & + & + & - & + \\
- & + & - & + & + & - & + \\
& + & - & + & + & - & +
\end{tabular}

+: Agglutination (Presence of C-reactive protein); -: No agglutination (Absence of C-reactive protein).

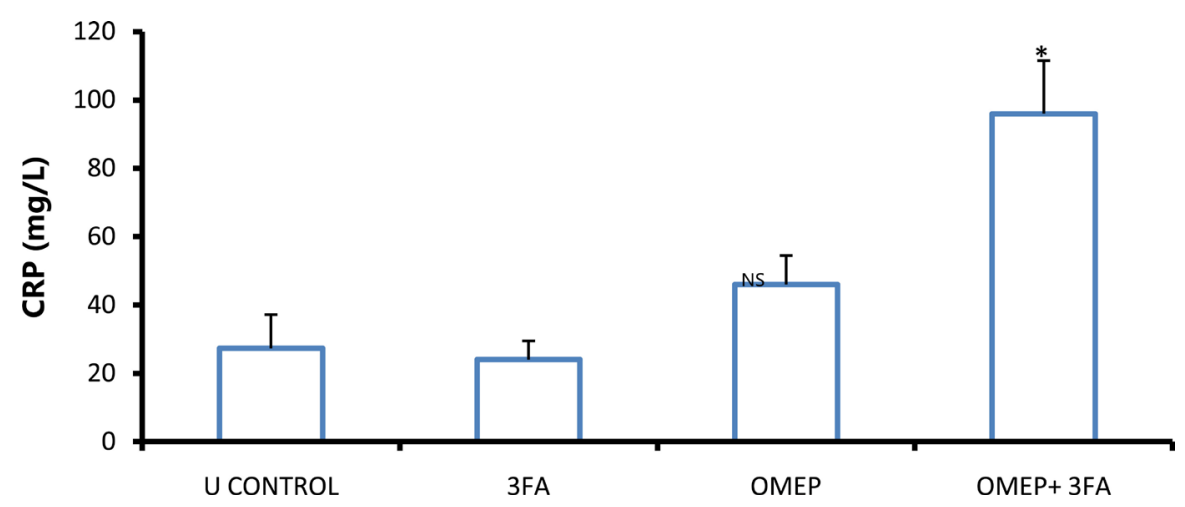

Control: Overall control group; U control: Ulcer control group; $2 \mathrm{FA}: 2 \mathrm{mg} / \mathrm{kg}$ folic acid; 3FA: 3 $\mathrm{mg} / \mathrm{kg}$ folic acid; OMEP: Omeprazole; OMEP + 2FA: Omeprazole and $2 \mathrm{mg} / \mathrm{kg}$ folic acid; OMEP + 3FA: Omeprazole and $3 \mathrm{mg} / \mathrm{kg}$ folic acid.

Figure 5. Effect of folic acid and omeprazole on C-reactive protein concentration post ethanol administration in rats $\left({ }^{*} \mathrm{p}<0.05 \mathrm{cf}\right.$ ulcer control).

\subsection{Immunohistochemical Analysis of p53 and BCl-2 in Ulcerated Stomach Pre-Treated with Folic Acid and Omeprazole}

An expression of p53 and $\mathrm{BCl}-2$ was observed in both ulcer untreated and treated groups which showed evidence of apoptotic process. Qualitatively, the 
ulcer control showed very mild surface/deep expression for $\mathrm{BCl}-2$ while the folic acid and omeprazole treated had focal or diffuse surface or deep expression (Plate 3). The reverse is observed for p53 intensity (Plate 4). Quantitatively, the labeling index in ulcer control was $45 \%$ and $15 \%$ for p 53 and BCl-2 respectively. Folic acid and omeprazole attenuated the expression of p53, and conversely enhanced BCl-2 as shown in Figure 6.

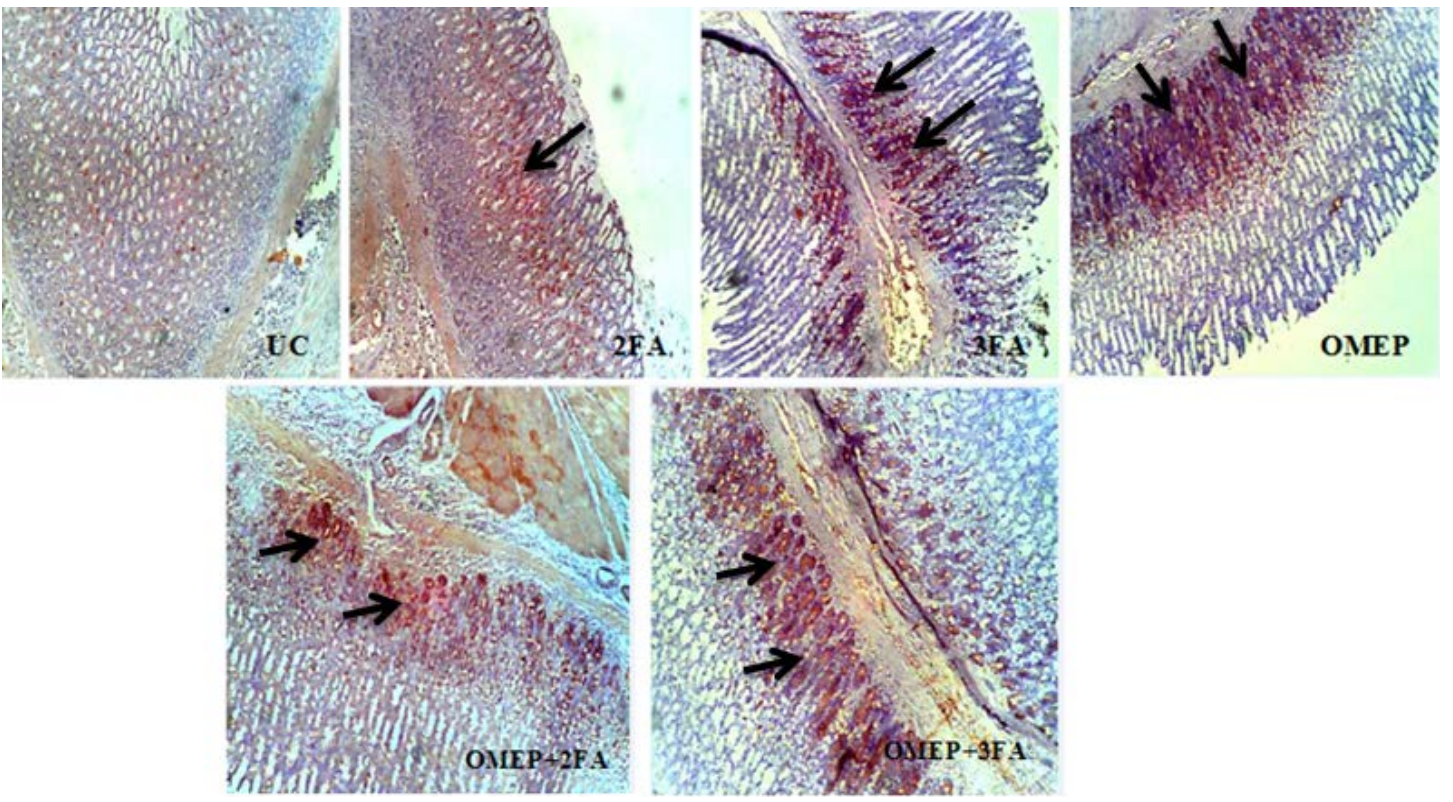

Plate 3. Immunohistochemical staining of BCl-2 in gastric ulcer treated with different doses of folic acid and omeprazole. UC: Ulcer control group; 2FA: $2 \mathrm{mg} / \mathrm{kg}$ folic acid; 3FA: $3 \mathrm{mg} / \mathrm{kg}$ folic acid; OMEP: Omeprazole; OMEP + 2FA: Omeprazole and $2 \mathrm{mg} / \mathrm{kg}$ folic acid; OMEP + 3FA: Omeprazole and $3 \mathrm{mg} / \mathrm{kg}$ folic acid. Black arrow: Positive immunoreactive area.
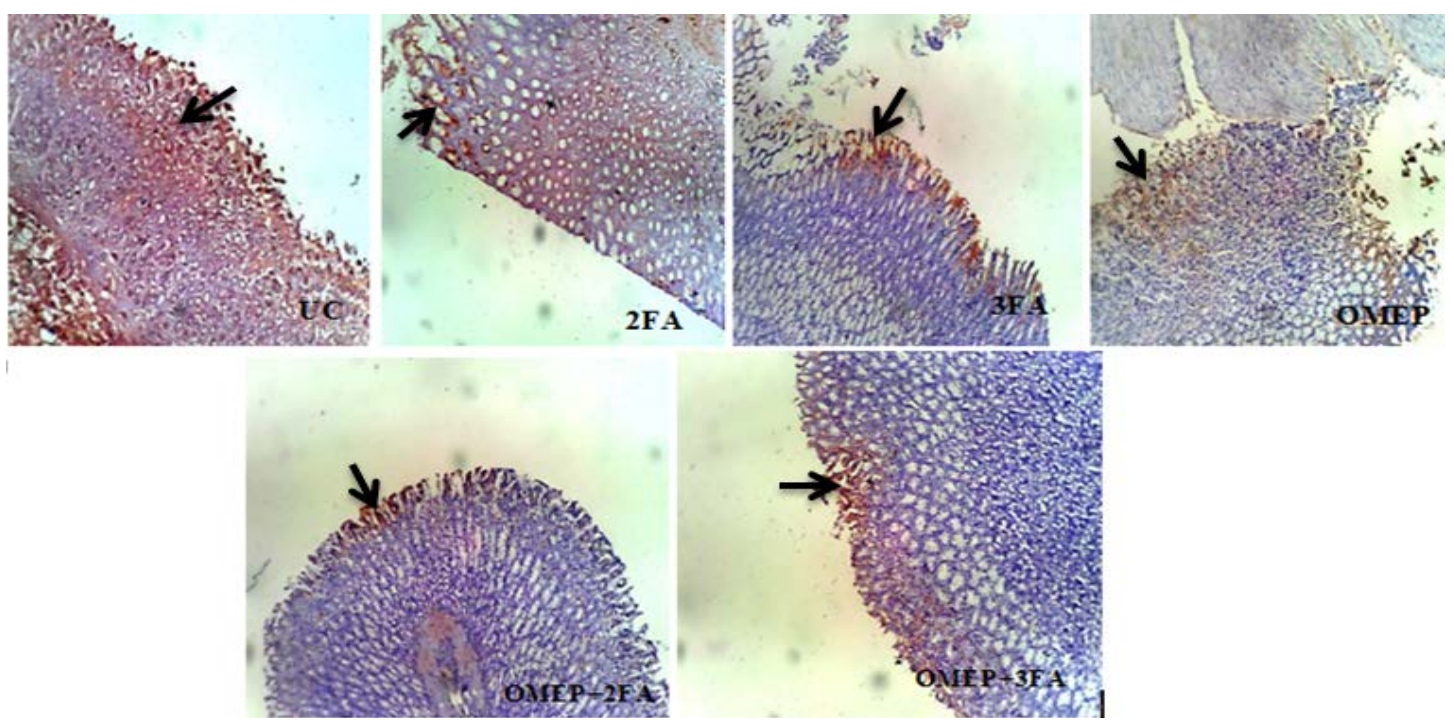

Plate 4. Immunohistochemical staining of p53 in gastric ulcer treated with different doses of folic acid and omeprazole. UC: Ulcer control group; 2FA: $2 \mathrm{mg} / \mathrm{kg}$ folic acid; 3FA: $3 \mathrm{mg} / \mathrm{kg}$ folic acid; OMEP: Omeprazole; OMEP + 2FA: Omeprazole and $2 \mathrm{mg} / \mathrm{kg}$ folic acid; OMEP + 3FA: Omeprazole and $3 \mathrm{mg} / \mathrm{kg}$ folic acid. Black arrow: Positive immunoreactive area. 
U CONTROL D2FA D3FA DOMEP DOMEP+2FA DOMEP+3FA

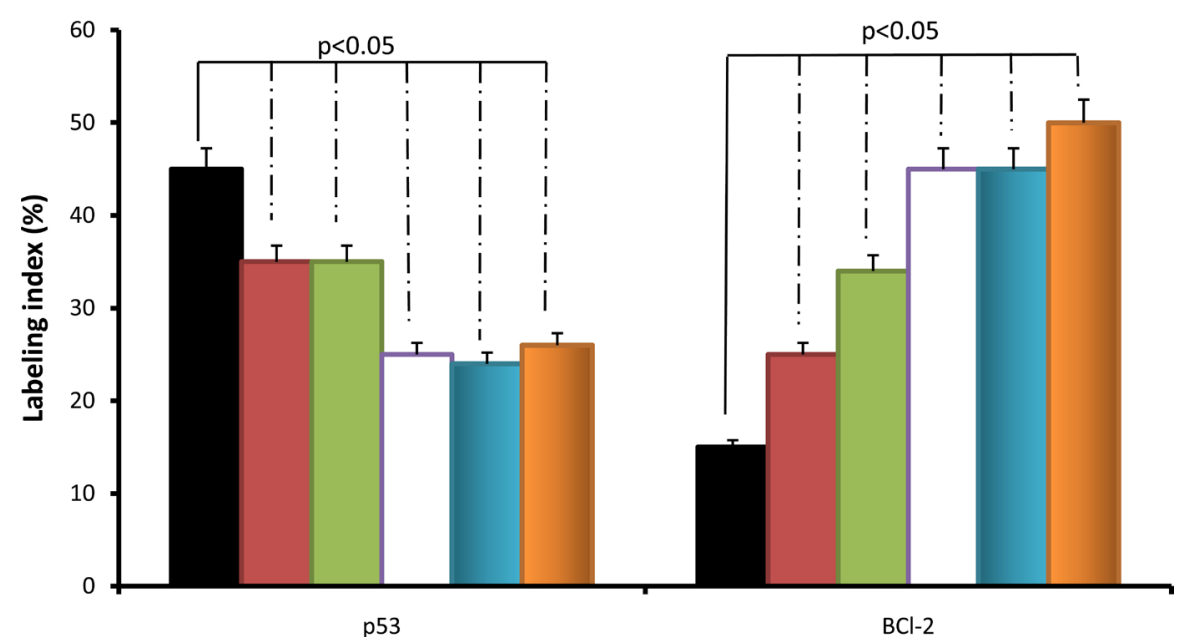

U control: Ulcer control group; 2FA: $2 \mathrm{mg} / \mathrm{kg}$ folic acid; 3FA: $3 \mathrm{mg} / \mathrm{kg}$ folic acid; OMEP: Omeprazole; OMEP + 2FA: Omeprazole and $2 \mathrm{mg} / \mathrm{kg}$ folic acid; OMEP + 3FA: Omeprazole and $3 \mathrm{mg} / \mathrm{kg}$ folic acid.

Figure 6. Labelling index of p53 and BCl-2 in ulcerated rat stomach pre-treated with folic acid and omeprazole ( $\mathrm{p}<0.05 \mathrm{cf}$ ulcer control).

\section{Discussion}

Ulceration of the gastric wall is manifested by heartburn, nausea, stomach pain and discomfort, and if left untreated can lead to bleeding, perforation and weight loss. The symptoms and discomfort accompanying the gastric ulcer impact on the quality of life, and accordingly social and economic implications [32]. Hence, the need to explore its therapy remains boundless.

In this study, intragastric administration of $95 \%$ ethanol caused characteristic ulcers in the rat glandular portion of the stomach. This is in agreement with previous reports on the effect of ethanol on gastric mucosa [33]. Pretreatment with the varying doses of folic acid caused significant inhibition of the ulcer lesions when compared with the ulcer control. Similarly, there was a significant reduction in the lesions formed in the animals pretreated with either omeprazole alone or combined with folic acid. Omeprazole has been extensively used to treat various ailments regarding gastric acid secretion [34]. Besides the anti-secretory effect of omeprazole in acid dependent ulcer models, it is well known to have mucosal protective effect [35], and the healing rates among patients suffering peptic ulcer are mainly due to its gastric mucosa protective effect, associated with the ability to suppress gastric juice acidity [36].

Ethanol induced ulcer is characterized by lipid peroxidation and neutrophil infiltration [37]. In the present study, ethanol induced lipid peroxidation (as assessed by malondialdehyde concentration) was reduced on pre-treatment with folic acid and omeprazole. Lipid peroxidation, which is a result of the reaction between oxyradicals and the polyunsaturated fatty acids, is not only an aggressive factor in the pathogenesis of gastric ulcer but also implicated in the delayed healing process in the gastric mucosa. Previous reports have implicated circu- 
lating activated and infiltrating leukocytes in the pathogenesis of ulcer models due to reduced gastric mucosal blood flow and microvascular dysfunction among other factors [38]. Neutrophils and other inflammatory cells, in particular, release reactive oxygen species, digestive enzymes and inflammatory cytokines such tumor necrosis factor alpha (TNFa), interleukins etc. at the ulcer sites [39]. In this study, we observed increase in inflammatory cells infiltration in control ulcerated animals which were reduced significantly in the folic acid and omeprazole treated groups.

Moreover, alteration of blood leukocytes, and specifically neutrophils is associated with inflammation [40]. The change in blood leukocyte counts signifies an immune response to unfavourable or abnormal situations [41]. Several studies have previously reported an association between leukocyte counts and cardiovascular disease [42], but now also peptic ulceration [43]. Besides, the neutrophil to lymphocyte count ratio (NLR) is now being regarded as a useful and reliable parameter for assessing some clinical problems ranging from cardiovascular events to cancer [44]. We observed in this study an increased total leukocyte count in the ulcer untreated group, which was reduced in the folic acid and omeprazole treated. Neutrophil-Lymphocyte Ratio (NLR) also followed the same pattern of reduction in the folic acid and omeprazole treated.

In the same vein, C-reactive protein (CRP) has been shown to be indicators of inflammation including peptic ulcers [45]. Pro-inflammatory mediators and cytokines initiate, at the site of ulcer, CRP from the liver which is a plasma protein, usually released in response to tissue inflammation. Elevated level of CRP is positive predictive value of peptic ulcer [46]. Substantial elevation in CRP was recorded in the ulcer control when compared with the overall control suggesting an intense inflammation after ethanol administration. Animals pre-treated with $2 \mathrm{mg} / \mathrm{kg}$ folic acid only, and combined with omeprazole showed no trace of CRP, but other groups showed sustained level. The reason for this is however unknown, though we suggest, may be due to sustained activation of leukocytes which is believed to be associated with proinflammatory cytokines release by the injured tissue [47]. Wu et al., [48] had earlier explained that serum CRP level correlates with serum interleukin (IL)-6 level, a key cytokine involved in the acute-phase response.

Investigations have long showed that the increase in gastric epithelial cells apoptosis is a prominent feature associated with mucosal injury upon acute ethanol administration. Apoptosis is essential mechanism of eliminating damaged or aged cells in order to maintain tissue integrity. Two central pathways that lead to apoptosis have been thoroughly explored in the study of gastric ulcerogenesis namely: positive induction by death factors binding to membrane receptors, and negative induction by loss of suppressor activity [49]. The positive induction is pro-apoptotic while negative induction is anti-apoptotic. The ratio of pro-apoptotic factors (e.g. p53, Bax, Bak, caspases) activity to anti-apoptotic (BCl-2) activity in the cell determines whether the cell death will be turned on and cascade of caspases, which are apoptosis executors, will be activated. Apop- 
tosis is expressed following acute mucosal injury and during gastric ulcer healing [50]. Our result was consistent with aforementioned because the apoptotic markers were significantly expressed in the ulcer untreated group. While p53 was suppressed in the folic acid and omeprazole treated, $\mathrm{BCl}-2$ was adequately enhanced. This suggests that folic acid may favour anti-apoptosis after the mucosal injury.

\section{Conclusion}

In conclusion, folic acid protects the gastric mucosa against acute injury induced by ethanol via anti-inflammatory and anti-apoptotic mechanisms. The combination of folic acid and omeprazole even offered an enhanced gastroprotection over either folic acid or omeprazole alone, thereby reiterating the importance of complementary use of dietary supplement in ulcer therapy.

\section{References}

[1] Wallace, J.L., Arfors, K.E. and McKnight, G.W. (1991) A Monoclonal Antibody against the CD18 Leukocyte Adhesion Molecule Prevents Indomethacin-Induced Gastric Damage in the Rabbit. Gastroenterology, 100, 878-883.

https://doi.org/10.1016/0016-5085(91)90259-N

[2] Tulassay, Z. and Herszényi, L. (2010) Gastric Mucosal Defense and Cytoprotection. Best Practice \& Research Clinical Gastroenterology, 24, 99-108. https://doi.org/10.1016/j.bpg.2010.02.006

[3] Allen, A. and Garner, A. (1980) Progress Report: Mucus and Bicarbonate Secretion in the Stomach and Their Possible Role in Mucosal Protection. Gut, 21, 249-262. https://doi.org/10.1136/gut.21.3.249

[4] Wallace, J.L. and Granger, D.N. (1996) The Cellular and Molecular Basis of Gastric Mucosal Defense. FASEB Journal, 10, 731-740.

[5] Herbay, A.V. and Rudi, J. (2000) Role of Apoptosis in Gastric Epithelial Turnover. Microscopy Research and Technique, 48, 303-311.

https://doi.org/10.1002/(SICI)1097-0029(20000301)48:5<303::AID-JEMT7>3.0.CO; $\underline{2-\mathrm{X}}$

[6] Yamaguchi, T., Nakajima, N., Kuwayama, H., Ito, Y., Iwasaki, A. and Arakawa, Y. (2000) Gastric Epithelial Cell Proliferation and Apoptosis in Helicobacter Pylori-Infected Mice. Alimentary Pharmacology \& Therapeutics, 14, 68-73. https://doi.org/10.1046/j.1365-2036.2000.014s1068.x

[7] Arab, H.H., Salama, S.A., Omar, H.A., Arafa, E.S.A. and Maghrabi, I.A. (2015) Diosmin Protects against Ethanol-Induced Gastric Injury in Rats: Novel Anti-Ulcer Actions. PLoS ONE, 10, e0122417. https://doi.org/10.1371/journal.pone.0122417

[8] Cao, D.Z., Sun, W.H., Ou, X.L., Yu, Q., Yu, T., Zhang, Y.Z., et al. (2005) Effects of Folic Acid on Epithelial Apoptosis and Expression of Bcl-2 and p53 in Premalignant Gastric Lesions. World Journal of Gastroenterology, 11, 1571-1576. https://doi.org/10.3748/wjg.v11.i11.1571

[9] Nicola, L.J., Andrew, S.D., Hilary, A.J. and Philip, M.S. (1999) Helicobacter pylori Induce Gastric Epithelial Cell Apoptosis in Association with Increased Fas Receptor Expression. Infection and Immunity, 67, 4237-4242.

[10] Konturek, P., Faller, P. and Marlicz, K. (1999) Antigastric Autoantibodies in 
Helicobacter pylori Infected Patients with Gastric Carcinoma: Implication of Plasma Gastrin Release and Gastric Secretory Functions. Gastroenterology, 116, A218.

[11] Nneli, R.O., Nwafia, W.C. and Oji, J.O. (2007) Diets/Dietary Habits and Certain Gastrointestinal Disorders in the Tropics: A Review. Nigerian Journal of Physiological Sciences, 22, 1-13.

[12] Li, Z., Zou, D., Ma, X., Chen, J., Shi, X., Gong, Y., Man, X. and Gao, L. (2010) Epidemiology of Peptic Ulcer Disease: Endoscopic Results of the Systematic Investigation of Gastrointestinal Disease in China. American Journal of Gastroenterology, 105, 2570-2577. https://doi.org/10.1038/ajg.2010.324

[13] Nwokediuko, S.C., Ijoma, U., Obienu, O. and Picardo, N. (2012) Time Trends of Upper Gastrointestinal Diseases in Nigeria. Annals of Gastroenterology, 25, 52-56.

[14] Thorsen, K., Soreide, J.A., Kvaloy, J.T., Glomsaker, T. and Soreide, K. (2013) Epidemiology of Perforated Peptic Ulcer: Age- and Gender-Adjusted Analysis of Incidence and Mortality. World Journal of Gastroenterology, 19, 347-354. https://doi.org/10.3748/wjg.v19.i3.347

[15] Niv, Y. (2008) Hpylori Recurrence after Successful Eradication. World Journal of Gastroenterology, 14, 1477-1478. https://doi.org/10.3748/wjg.14.1477

[16] Ito, T., Cadiot, G. and Jensen, R.T. (2012) Diagnosis of Zollinger-Ellison Syndrome: Increasingly Difficult. World Journal of Gastroenterology, 18, 5495-5503. https://doi.org/10.3748/wjg.v18.i39.5495

[17] Wilhelm, M.S., Ryan, R.G. and Kale-Pradhan, P.B. (2013) Perils and Pitfalls of Long Term Effects of Proton Pump Inhibitors. Expert Review of Clinical Pharmacology, 6, 443-451. https://doi.org/10.1586/17512433.2013.811206

[18] Pereira, R.S. (2006) Regression of Gastroesophageal Reflux Disease Symptoms using Dietary Supplementation with Melatonin, Vitamins and Amino Acids: Comparison with Omeprazole. Journal of Pineal Research, 14, 195-200. https://doi.org/10.1111/j.1600-079X.2006.00359.x

[19] Celinski, K., Konturek, P.C., Konturek, S.J., Slomka, M., Cicoz-Lach, H., Brozozowski, T. and Bielanski, W. (2011) Effects of Melatonin and Tryptophan on Healing of Gastric and Duodenal Ulcers with Helicobacter pylori Infection in Humans. Journal of Physiology and Pharmacology, 62, 521-526.

[20] Kim, Y.I. (2003) Role of Folate in Cancer Development and Progression. Journal of Nutrition, 133, 3731S-3739S.

[21] Temple, C.T. and Montgomery, J.A. (1984) Chemical and Physical Properties of Folic acid and Reduced Derivatives. In: Blackey, R.L. and Benkovic, S.J., Eds., Folates and Pterins, Vol. 1, Chemistry and Biochemistry of Folates, 2nd Edition, John Wiley and Sons, New York, 61-120.

[22] Lucock, M. (2004) Is Folic Acid the Ultimate Food Component for Disease Prevention? BMJ, 328, 211-214. https://doi.org/10.1136/bmj.328.7433.211

[23] Ajeigbe, K.O., Olaleye, S.B., Oladejo, E.O. and Olayanju, A.O. (2011) Effect of Folic Acid Supplementation on Oxidative Gastric Mucosa Damage and Acid Secretory Response in the Rat. Indian Journal of Pharmacology, 43, 578-581. https://doi.org/10.4103/0253-7613.84976

[24] Ajeigbe, K.O., Oladejo, E.O., Emikpe, B.O., Asuk, A.A. and Olaleye, S.B. (2012) The Dual Modulatory Effect of Folic Acid Supplementation on Indomethacin Induced Gastropathy. The Turkish Journal of Gastroenterology, 23, 639-645. https://doi.org/10.4318/tjg.2012.0423 
[25] Haule, E.E., Moshi, M.J., Nondo, R.S., Mwangomo, D.T. and Mahunnah, R.L. (2012) A Study of Antimicrobial Activity, Acute Toxicity and Cytoprotective Effect of a Polyherbal Extract in a Rat Ethanol-HCl Gastric Ulcer Model. BMC Research Notes, 5, 546. https://doi.org/10.1186/1756-0500-5-546

[26] Gutteridge, J.M.C. and Wilkins, S. (1982) Copper-Dependent Hydroxyl Radical Damage to Ascorbic Acid: Formation of a Thiobarbituric Acid Reactive Product. FEBS Letters, 137, 327-330. https://doi.org/10.1016/0014-5793(82)80377-3

[27] Hunter, G.D., Millson, G.C. and Chandler, R.L. (1963) Observations on the Comparative Infectivity of Cellular Fractions Derived from Homogenates of Mouse-Scrapie Brain. Research in Veterinary Science, 4, 543-549.

[28] Ogihara, Y. and Okabe, S. (1993) Effect and Mechanism of Sucralfate on Healing of Acetic Acid-Induced Gastric Ulcers in Rats. Journal of Physiology and Pharmacology, 44, 109-118.

[29] Haber, M.M. and Lopez, I. (1999) Gastric Histologic Findings in Patients with Nonsteroidal Anti-Inflammatory Drug-Associated Gastric Ulcer. Modern Pathology, 12, 592-598.

[30] Trevethick, M.A., Clayton, N.M., Strong, P. and Harman, I.W. (1993) Do Infiltrating Neutrophils Contribute to the Pathogenesis of Indomethacin Induced Ulceration of the Rat Gastric Antrum? Gut, 34, 156-160.

https://doi.org/10.1136/gut.34.2.156

[31] Wang, J., Fan, X., Lindholm, C., Bennett, M., O’Connoll, J., Shanahan, F., et al. (2000) Helicobacter pylori Modulates Lymphoepithelial Cell Interactions Leading to Epithelial Cell Damage through Fas/Fas Ligand Interactions. Infect Immunity, 68, 4303-4311. https://doi.org/10.1128/IAI.68.7.4303-4311.2000

[32] Yuan, Y., Padol, I.T. and Hunt, R.H. (2006) Peptic Ulcer Disease Today. Nature Clinical Practice Gastroenterology \& Hepatology, 3, 80-89. https://doi.org/10.1038/ncpgasthep0393

[33] Piotrowski, J., Piotrowski, E., Skrodzka, D., Slomiany, A. and Slomiany, B.L. (1997) Gastric Mucosal Apoptosis Induced by Ethanol: Effect of Antiulcer Agents. Biochemistry and Molecular Biology International, 42, 247-254. https://doi.org/10.1080/15216549700202631

[34] Lind, T., Cederberg, C., Ekenved, G., Haglund, U. and Olbe, L. (1983) Effect of Omeprazole-A Gastric Proton Pump Inhibitor on Pentagastrin Stimulated Acid Secretion in Man. Gut, 24, 270-276. https://doi.org/10.1136/gut.24.4.270

[35] Tsuji, S., Sun, W., Tsujii, M., Kawai, N., Kimura, A., Kakiuchi, Y., Yasumaru, S., Komori, M., Murata, H., Sasaki, Y., Kawano, S. and Hor, M. (2002) Lansoprazole Induces Mucosal Protection through Gastrin Receptor-Dependent Up-Regulation of Cyclooxygenase-2 in Rats. Journal of Pharmacology and Experimental Therapeutics, 303, 1301-1308. https://doi.org/10.1124/jpet.102.035204

[36] Tang, R.S.Y. and Wu, J.C.Y. (2013) Managing Peptic Ulcer and Gastroesophageal Reflux Disease in Elderly Chinese Patients-Focus on Esomeprazole. Clinical Interventions in Aging, 8, 1433-1443.

[37] Kobayashi, T., Ohta, Y., Yoshino, J. and Nakazawa, T. (2001) Teprenone Promotes the Healing of Acetic Acid-Induced Chronic Gastric Ulcers in Rats by Inhibiting Neutrophil Infiltration and Lipid Peroxidation in Ulcerated Gastric Tissues. Pharmacological Research, 43, 23-30. https://doi.org/10.1006/phrs.2000.0748

[38] Musumba, C., Pritchard, D.M. and Pirmohamed, M. (2009) Cellular and Molecular Mechanisms of NSAIDs-Induced Peptic Ulcers. Alimentary Pharmacology \& Therapeutics, 30, 517-531. https://doi.org/10.1111/j.1365-2036.2009.04086.x 
[39] Dovi, J.V., Szpaderska, A.M. and Dipietro, L.A. (2004) Neutrophil Function in the Healing Wound: Adding Insult to Injury. Thrombosis and Haemostasis, 92, 275-280. https://doi.org/10.1160/TH03-11-0720

[40] Nagatomi, R. (2006) The Implication of Alterations in Leukocyte Subset Counts on Immune Function. Exercise Immunology Review, 12, 54-71.

[41] De Jager, C.P., Wijk, P.T., Mathoera, R.B., De Jongh-Leuvenink, J., Poll, V.T. and Wever, P.C. (2010) Lymphocytopenia and Neutrophil-Lymphocyte Count Ratio Predict Bacteremia Better than Conventional Infection Markers in an Emergency Care Unit. Critical Care, 14, R192. https://doi.org/10.1186/cc9309

[42] Huang, G., Zhong, X.N. and Zhong, B. (2009) Significance of White Blood Cell Count and Its Subtypes in Patients with Acute Coronary Syndrome. European Journal of Clinical Investigation, 39, 348-358.

https://doi.org/10.1111/j.1365-2362.2009.02107.x

[43] Jafarzadeh, A., Akbarpoor, V., Nabizadeh, M., Nemati, M. and Rezayati, M.T. (2013) Total Leukocyte Counts and Neutrophil-Lymphocyte Count Ratios among Helicobacter Pylori-Infected Patients with Peptic Ulcers: Independent of Bacterial CagA Status. The Southeast Asian Journal of Tropical Medicine and Public Health, 44, 82-88.

[44] Ubukata, H., Motohashi, G., Tabuchi, T., Nagata, H. and Konishi, S. (2010) Evaluations of Interferon-Gamma/Interleukin-4 Ratio and Neutrophil/Lymphocyte Ratio as Prognostic Indicators in Gastric Cancer Patients. Journal of Surgical Oncology, 102, 742-747. https://doi.org/10.1002/jso.21725

[45] Droogendijk, J., Beukers, R., Berendes, P.B., Tax, M.G., Sonneveld, P. and Levin, M.D. (2011) Screening for Gastrointestinal Malignancy in Patients with Iron Deficiency Anemia by General Practitioners: An Observational Study. Scandinavian Journal of Gastroenterology, 46, 1105-1110.

https://doi.org/10.3109/00365521.2011.594082

[46] Boehme, M.W., Autschbach, F., Ell, C. and Raeth, U. (2007) Prevalence of Silent Gastric Ulcer, Erosions or Severe Acute Gastritis in Patients with Type 2 Diabetes Mellitus-A Cross-Sectional Study. Hepatogastroenterol, 54, 643-648.

[47] Hawley, T.S., Burns, B.F. and Hawley, R.G. (1991) Leukocytosis in Mice Following Long-Term Reconstitution with Genetically-Modified Bone Marrow Cells Constitutively Expressing Interleukin 1 Alpha or Interleukin 6. Leukemia Research, 15, 659-673. https://doi.org/10.1016/0145-2126(91)90068-5

[48] Wu, C.W., Wang, S.R., Chao, M.F., Wu, T.C., Lui, W.Y., P’eng, F.K. and Chi, C.W. (1996) Serum Interleukin-6 Levels Reflect Disease Status of Gastric Cancer. The American Journal of Gastroenterology, 91, 1417-1422.

[49] Szabo, I. and Tarnawski, A.S. (2000) Apoptosis in Gastric Mucosa: Molecular Mechanisms, Basic and Clinical Implications. Journal of Physiology and Pharmacology, 51, 3-15.

[50] Stachura, J., Tarnawski, A. and Dabros, W. (1993) Apoptosis: Genetically Programmed Physiological Cell Loss in Normal Gastric Oxyntic Mucosa and in Mucosa of Grossly Healed Gastric Ulcer. Journal of Clinical Gastroenterology, 17, S70-S77. https://doi.org/10.1097/00004836-199312001-00015 